\title{
Study on Landscape Planning and Design of Jielong Village in Xinhua County against the Background of Rural Revitalization
}

\author{
Tan Juan, Pan Jingjing \\ Hunan University of Humanities, Science and Technology \\ Loudi, Hunan, 417000
}

\begin{abstract}
In recent years, we are experiencing the first five year of rural revitalization strategy. For the countryside development in China, there are rare opportunities as well as great challenges. It is a practical problem faced by us when planning the rural landscapes as to how to conduct rural construction and narrow the gap between rual and urban districts. Jielong Village, Xinhua County, is a pilot village of new countryside as well as beautiful village. In this paper, we start with Jielong Village landscapes for the beautiful countryside construction and try to reflect the element of nostalgic memories on the theme of ecology and nature. We give consideration to both function and aesthetic value, fully explore the regional culture, protect and inherit historical traditions. At the same time, human settlement, development of agriculture and tourism are integrated.
\end{abstract}

Keywords-landscape design; new countryside; rural rejuvenation and nostalgia

\section{INTRODUCTION}

According to "Rural Revitalization Strategy and Plan of Hunan Province (2018-2022)" released in Hunan province, it is a basic task of rural rejuvenation in Hunan province to build eco-friendly and livable beautiful village, inherit rural culture and keep nostalgic memories[1]. As for landscape planning and design in Jielong Village, there are 8 landscapes that will be built. Three measures will be taken in combination to reflect the element of nostalgic memories in an integrated way.

\section{General Situation OF JiELONG ViLlage}

Jielong Village is located in the southeast of Shangmei Town, Xinhua County, Loudi City, Hunan Province, with Zijiang River on the east, and it is faced with Sangzi. It is ajacent to Dashuiping Village, Shangmei Town, on the west and Longjiaqiao Village, Shichongkou Town on the south. There are 9 villagers' residential courtyards and 18 groups of villagers in the whole village, with permanent population of 2053[2].

Jielong Village enjoys advantage of geographical location and significant advantage of geographical location. S70 Louhuai Expressway and Shanghai-Kunming Railway passes through the village, and Zijiang River flows from the southeast to the west. The total mileage of paved roads in the village is
3.8 kilometers, and it is about 13 kilometers from Xinhua County to the village. G354 Loudi Avenue under construction passes through Jielong Village, and it is only 8 minutes drive to the county and Lengshuijiang City after it is completed. The village aims to develop characteristic agriculture and Leisure Agriculture, and it is backyard garden and supply base of special agricultural products for Xinhua County and Lengshuijiang City [3].

The enterprises located in Jielong Village included Xianghan Waxberry Planting Cooperatives, vegetable planting cooperatives, grape planting cooperatives and so on; and the main agricultural products include waxberry, grape, grapefruit, vegetables, livestock and so on [4].

\section{PROJECT ORIENTATION}

The project is a field project for Xinhua County, Loudi City, and its specialty industries include 2000 acres of waxberry base, natural well water lake, tea garden base and Chutouwa ecology village etc. With unique advantage of geographical location (only 15 minutes' drive to the urban area), Jielong Village will be built into a comprehensive rural development model which integrates modern agriculture, leisure tourism and rural communities. The road and traffic problems will be solved to perfect supporting services for the infrastructure. The problem of employment will be solved from some of villagers of Jielong Village by promoting agricultural development through tourism and integration of three industries, so as to improve the living standards of dwellings in Jielong Village [5].

\section{PLANNING CONCEPT}

The village will explore the tourism resource of modern agriculture, develop tourism industry based on the local characteristics and accelerate the rural rejuvenation.

First, perfect the supporting facilities: develop supporting services and supporting basic equipment and perfecting community support.

Second, it is necessary to enhance the road network: the transportation system will be perfect by combining current road status and development needs, and supporting public facilities and portal layout will be provided. 
Third, industrial integration: the original resources will be utilized to reform, improve and explore the development of emerging industry. Sustainable development model can be realized by combining them.

Fourth, the function division and planning should be made: by combing landscape with agriculture, the visual feast of field landscape is created, and the agriculture is more than agriculture.

Fifth, physical planning and construction of new residential quarters is emphasized: some of buildings will be designed and turned into courtyard homestay, and a uniform external facade construction will be made. Based on construction, renovation and replacement of scenic area, the element of Meishan culture is integrated to reflect the nostalgic memory.

\section{PlanNING GOAL}

Jielong Village will be turned into a rural garden complex which integrates modern agriculture, leisure tourism and rural communities, so as to improve the living standards of villagers of Jielong Village.

\section{PLANNING INSTRUCTIONS}

First, Entryways of new residential quarters: the entryways are located at the junction of Loudi Avenue and Guangyi Entrance, and the tourist would be impressed by the good image of Jielong Village at the sight of the gate[6].

Rectangle steles are set in the middle of entrance way, which will be engraved with the name of Jielong Village. Counterflow separation will be realized on the road to highlight the entrance and control the traffic in case congested traffic occurs, and the traveling safety can be guaranteed.

Second, flower photography base: there will be large areas of sunflower flower fields at the entrance of the base, and landscape and scenery are extremely beautiful when the sunflowers are blooming. It is also suggested that rape, Lavender, roses, Cherry blossom and peach blossoms and other flowers are planted to make sure that there are flowers all around the years so that the tourists can enjoy a good photographing time.

Third, Cultural Square: the square is located near the junction between the southern Jielong Village and S70 Louxin Expressway, and it is also the secondary entrance to Jielong Village. "Nostalgic elements" are created as landscapes on the Cultural Square, so that nostalgic elements become visible and tangible objects, so that the villagers will have a place for leisure, entertainment and fitness. Activities such as Fitnessfor-All and Dancing Villagers etc. will be organized to promote villagers' sense of identity with the village. (As per Figure 1)

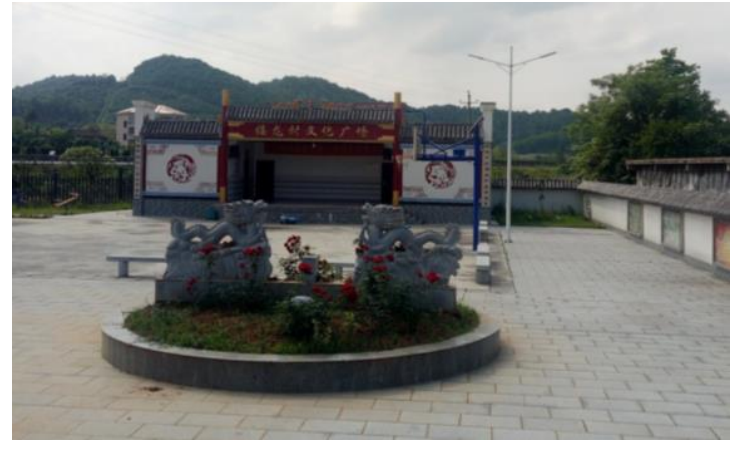

Fig. 1 Cultural Square of Jielong Village

Fourth, ecological farm village: the tourists will be encouraged to experience the farming culture of the past, and they can have fun with agricultural production when they engage in agricultural activities. There are greenhouses of vegetable and fruits, poultry and agritainment and so on. (As per Figure 2)

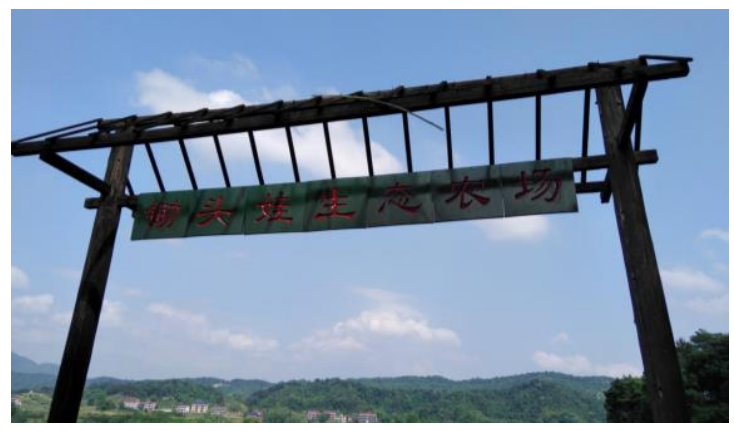

Fig. 2 Chutouwa Ecological Farm of Jielong Village

Fifth, Tan's Ancestral Temple: Tan's Ancestral Temple is located near the secondary entrance, and the style and atmosphere of Jielong Village featured by historical culture and art is highlighted. Through planning and design, the local traditional culture is displayed, that is, nostalgia, the feature of Meishan culture. (As per Figure 3)

Sixth, Tea fields in the Mountains: tea fields are located on the left side of main entryways. There are a lot of tea fields in the mountains, and a Wangcha Pavilion will be built at the peak of mountains where the villagers and tourists can take a rest and appreciate the beautiful sceneries of tea fields. Moreover, a Tea House will be set, and tourists can take a rest and appreciate tea art performance and purchase the local specialties and teas.

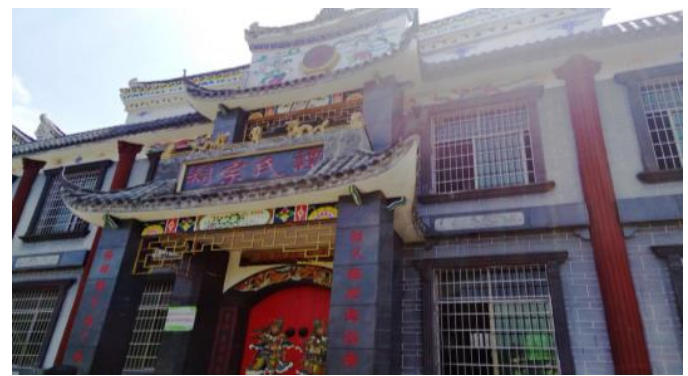

Fig. 3 Tan's Ancestral Temple of Jielong Village 
Seventh, tea making workshop: a tea making workshop is built neat the tea fields, where the picked fresh tea leaves are processed, manufactured, packed and sold. The workshops will create employment posts for Jielong Village to alleviate the empty nest phenomenon and improve tea value.

Eighth, landscape avenue: landscapes wooden trestle will be built along the Zishui River, and trees with great ornamental values such as cherries will be planted along the bank. Waterside platform will be built so that the tourists and the villagers can appreciate the waterscape at their leisure. Activities such as fishing base and Fishing Boat In the Evening can be developed so that the tourists and the villagers can get relaxed through the rural life.

Ninth, 300-meter fitness runway: a fitness runway is built near the hillside, so that the villagers can take morning exercise or take a relaxing walk after the meal. Ecological long-distance running is a best choice, and village committee will also arrange 3000-meter outdoor long-distance race regularly, which not only encourages the villagers of Jielong Village to build up their body, but also provide good prorogation effect for the construction of new countryside.

Tenth, Service and reception area: Service and reception area is set at the central area of Jielong Village so that tourists can know the entire regional planning in a short time, and the service and reception provides the tourists with all kinds of services such as lost and found, luggage deposit, medical services, Postal Service, Facilities for the Disabled and so on. (As per Figure 4)

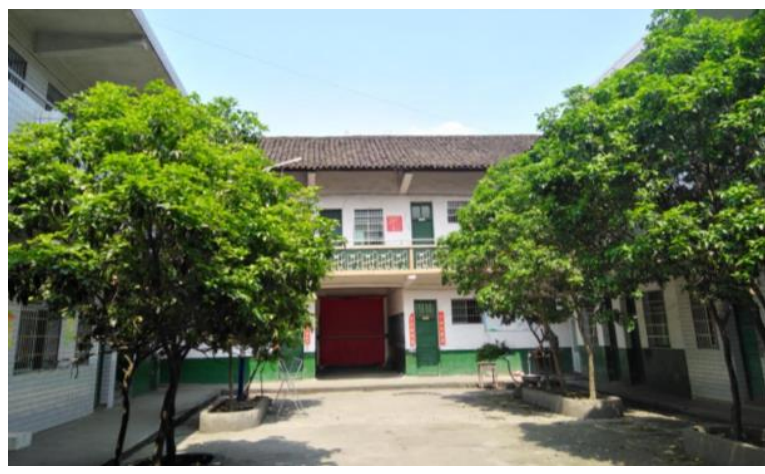

Fig. 4 Tan's Ancestral Temple of Jielong Village

Eleventh, recreational and entertainment area: it is a place where villagers and tourists can go sightseeing, tourism, leisure, and vegetable and fruit picking to actually enjoy the fun of the countryside. Therefore, the rural landscapes and interests are created, that is, a memorable rural experience.

Twelfth, Orchard for organic fruit and vegetable picking: Orchard for organic fruit and vegetable picking is built, and special fruit trees are planted so make sure that there are fruits to pick all the year around. The tourists can go sightseeing and experiencing agricultural activities, and the orchard is designed to show a consumptive idea featured by freedom, delight in the wild and returning to nature.

\section{CONCLUSION}

In recent years, rural construction attracted people's attention, and a series of laws are promulgated such as the Urban and Rural Planning Law etc., which are of far-reaching significance for promoting the overall civilization of China. In this paper, the current situation and problems involved in the landscapes building for beautiful countryside construction in Jielong Village, Xinhua County, are solved. It is suggested that the local Meishan culture is combined with tourism development by building a rural complex which is consistent with the policy of construction of beautiful countryside in the new era to create nostalgic culture that belongs to Jielong Village and extract signs of nostalgic culture. The characteristic rural style of Jielong Village is formed and the special nostalgic atmosphere of Jielong Village is created. The tourism industry is developed to revitalizes rural resources, enrich villagers' life and build a beautiful village.

\section{ACKNOWLEDGMENT}

Tan Juan (November, 1985 - ), female, is from Xinhua, Hunan. She is a doctoral student, and lecturer of School of Fine Arts and Design, Hunan University of Humanities, Science and Technology. Research direction: environmental design.

Pan jingjing(1997-), female, undergraduate, Hunan University of Humanities, Science and Technology. Research direction: environmental design.

\section{REFERENCES}

[1] Xiong Yingwei. Liu Hongtao. Yang Jian. Rural Planning and Design. Nanjing: Southeast University Press, August 2017

[2] Lei Zhaohui. Case Study on the Status Quo of Rural Revitalization and Planning and Design Strategy[J]. China Construction, 2018(11): 94-95.

[3] Lu Bin. The current situation and development of rural landscape design in landscape planning [J]. China New Technology and New Products, 2019 (01): 132-133.

[4] Yang Yeke. Architectural characteristics and color planning analysis of the pastoral complex [J]. Jushe, 2019 (01): 113.

[5] Yuan Fengzhu. Research on rural imagery in beautiful rural construction [D]. Anhui Agricultural University, 2018.

[6] Liu Xiaoyu. Research on characteristic the rural planning strategy of Suzhou in the context of rural revitalization [D]. Suzhou University of Science and Technology, 2018. 